\title{
Miscellaneous
}

Borut Trpin*

\section{Conference Report: The Third Conference of the East European Network for Philosophy of Science (EENPS 2021), 9-11 June, 2021}

https://doi.org/10.1515/krt-2021-0016

Published online June 29, 2021

Between June 9 and June 11, 2021 approximately 80 speakers participated at the third East European Network for Philosophy of Science (EENPS) conference that took place in a hybrid format, online and in person at the Faculty of Philosophy, University of Belgrade in Serbia.

The EENPS was founded in 2015 by the fellows of the first cohort of European Philosophy of Science (EPSA) fellowship scheme for junior philosophers working in Central and Eastern Europe. Not to overlap with EPSA biannual conferences, the EENPS decided to organize its conferences in even years: the first conference took place in Sofia, Bulgaria in 2016 and the second in Bratislava, Slovakia 2018. The third conference of the network was likewise planned for June 2020, but it was delayed for one year because of the pandemic. Select papers from each conference have been published in special issues of various journals - this year they will be published in International Studies in the Philosophy of Science (ISPS).

The participants joined from all over the world, which also fulfilled one of the main aims of the network: to foster connections between philosophers of science working in Central and Eastern Europe (the network's focal region) and those working in Western Europe and elsewhere. The conference provided a good variety of topics, ranging from general philosophy of science to philosophy of specific sciences, history and philosophy of science, formal philosophy of science, and philosophy of mathematics and logic, and had two keynote talks, given by Anna Alexandrova (University of Cambridge) and Gerhard Schurz (University of Düsseldorf).

The next conference of the EENPS will take place in summer 2022 in Tartu, Estonia, and we expect that it will attract even more submissions and that by then it

\footnotetext{
*Corresponding author: Borut Trpin, Munich Center for Mathematical Philosophy, LudwigMaximilians-Universitat Munchen, Geschwister-Scholl-Platz 1, 80539 Munchen, Germany, E-mail: borut.trpin@lrz.uni-muenchen.de
} 
will be possible to hold it in person. If not, the Belgrade conference serves as a proof that it is possible to successfully conduct an event of this size online or in a hybrid format.

\section{Some Numbers}

About 80 speakers presented approximately 70 contributed talks in regular sessions and four symposia over three days, in which the conference went on in 2-3 parallel sessions. The EENPS is a growing network: the conference attracted 120 submitted abstracts (compared to 64 and 37 submissions in the previous years). Although one of the principles behind the network's conference is to be inclusive and therefore to keep the rejection rate relatively low, the increased number of submissions meant that the rejection rate increased to approximately $26 \%$ (compared to 20 and 13.5\% in 2018 and 2016, respectively). Precise statistics about the countries of participants were not collected, but a glance at the program ${ }^{1}$ reveals a balanced mixture of speakers from Central and Eastern Europe (especially Serbia, Poland, Greece) and other regions (e.g., Italy, Germany, USA). Reflecting the general situation in philosophy of science, gender balance could unfortunately not be fully achieved: only about $27 \%$ of the speakers were female. The network recognizes this problem and is considering mentoring activities to encourage greater representation by non-male philosophers of science.

\section{Keynote Talks}

The conference opened with a keynote talk Social Science: A Constructivist Account by Anna Alexandrova (University of Cambridge). Alexandrova, who originally comes from Russia, started her talk by mentioning how valuable the EENPS is in supporting scholars from Eastern Europe with their specific problems and that she wishes the network was already established when she was entering academia. In the talk, Alexandrova then discussed the issues related to defining social science. She addressed two opposing views: that social science should be seen as analogous to natural sciences for questions related to society, or alternatively that it should be seen as something different from natural sciences and humanities. She argued that both views are unsatisfactory and proposed that social science should be defined in a constructivist way as any form of knowledge that helps a community in better understanding and improving itself.

1 See: https://eenps.weebly.com/schedule.html. 
Gerhard Schurz (University of Düsseldorf) opened the last day of the conference with a keynote talk Abduction in Science and Metaphysics. In the talk, Schurz discussed what abduction is and how it can be selective (select the best of available explanations) and creative (create a new explanation). He then focused on speculative abduction in metaphysics and analysed it in comparison to abduction in science. It seems that the two are quite different - speculative abductions cannot be independently tested and may not provide unification. However, as Schurz convincingly argued, the two are actually more alike than it may seem on the first sight and both may be justified by the optimality of meta-induction (see also Schurz 2019). Both keynote talks were followed by a lively Q\&A discussion.

\section{Contributed Talks}

Participants of the conference presented 49 contributed talks in 12 separate sessions. The sessions were devoted to various themes ranging from general philosophy of science (e.g., explanation, understanding, causation), philosophy of social sciences (e.g., economics), philosophy of medicine, philosophy of cognitive science, philosophy of biology, philosophy of physics, history and philosophy of science, formal philosophy of science, and philosophy of mathematics and logic. The breadth may be seen by mentioning some talks: Lilia Gurova (NBU Sofia) discussed factivist and non-factivist accounts of scientific understanding, Predrag Šustar and Zdenka Brzović (Rijeka) discussed function acquisition in genomics, Samuele Iaquinto (Turin) and Claudio Calosi (Geneva) talked about quantum fragmentalism, and Michael Shenefelt and Heidi White (NYU) about the emergence of symbolic logic during the industrial revolution. The abstracts of all talks are available at the conference website. ${ }^{2}$

\section{Symposia}

On the first day, four talks were also given in a symposium (organised by Máté Szabó, Oxford) on the rich history of formal logic in Eastern Europe, which is too often overlooked. Two symposia took place on the second day: the first with seven talks on free will and consciousness as a problem of philosophy of science (organised by Louis Vervoort, Tyumen, and Maria Sekatskaya, Düsseldorf), and the second on psychology and philosophy of science with five talks (organised by Vlasta Sikimić, Tübingen, Kaja Damjanović, Belgrade, Marko Tešić, Birkbeck, Nora

2 See: https://eenps.weebly.com/book-of-abstracts.html. 
Hangel, TUM, and Tijana Nikitović, Belgrade). The former symposium demonstrated the breadth of philosophy of science and the latter showed the importance of empirical approaches in it. The last symposium with four talks took place on the final day. It was devoted to trends in formal philosophy of science (organised by Vlasta Sikimić, Tübingen, Jan Sprenger, Turin, Borut Trpin, LMU/MCMP, and Sandro Radovanović, Belgrade). An interesting point was, for example, made by Jan Sprenger that there is no clear cut between science and scientific philosophy.

The symposia provided an excellent enrichment of the program as the talks were thematically connected, while the speakers in each symposium came from different universities and countries. Moreover, all symposia attracted a number of listeners and all talks led to a dynamic discussion.

\section{Conclusion}

The EENPS supports early-career researchers and students. Thus, the day after the conference, the international conference for Students of Analytic Philosophy (ic.SoAP 2021, organised by Michal Hladky, Kyryll Khromov, both Geneva, and Federico Donato, Lugano) took place as an EENPS satellite student event with six excellent talks on various topics, among other also in philosophy of science. An interested reader is encouraged to check the event's website where abstracts of the talks may also be found. ${ }^{3}$

Special thanks for organising the conference go to the local organising team led by Duško Prelević who organised a relatively large event in a hybrid format. The conference would also not be possible without the help of 28 members of the programme committee who were involved in the peer review process. The committee was co-chaired by Barbara Osimani (Università Politecnica delle Marche) and the author of this report. For further details about the members of the program committee and the local organising team, see the conference website. ${ }^{4}$

The EENPS is an inclusive network and encourages philosophers of science, regardless of their residence or origin, to join. The membership in the network is free and comes with a number of other initiatives besides the conference, e.g., an online seminar, a reading group, and social media channels to promote the research of its members.

3 See: https://icsoap.wordpress.com/ic-soap-2021-eenps/.

4 See: https://eenps.weebly.com/program-committee2.html. 
Acknowledgement: Thanks to Vlasta Sikimić for providing very useful feedback on an earlier version of this report.

Research funding: This report was funded by the Alexander von Humboldt Foundation.

\section{Reference}

Schurz, G. 2019. Hume's Problem Solved: The Optimality of Meta-Induction. Cambridge: MIT Press. 